\title{
Cytokine antagonists and their potential therapeutic use
}

\author{
Reno Debets and Huub F.J. Savelkoul
}

Unraveling the interactions between cytokines and cytokine receptors is of crucial importance to the design of specific cytokine antagonists. A general finding in this respect is iliustrated by studies in which mice that are made deficient in cytokine receptors, by gene targeting, are more-severely affected than anticipated, possibly due to sharing of receptor chains by different cytokine receptors (J. Peschon, Seattle). By contrast, ligand (cytokine)-deficient mice appear to be less affected than anticipated, which may be due to the redundancy of cytokines. Nature confirms these findings: the severe combined immunodeficiency (SCID) mutation and the hyper-IgM syndrome are consequences of interleukin 2 receptor (IL-2R) $\gamma$-chain and CD40 ligand (L) deficiencies, respectively.

The in vivo relevance of (soluble) cytokine receptors has also been illustrated by several viruses. Vaccinia and cowpox viruses encode a protein in their open reading frame (ORF) that displays homology with soluble IL-1R type II and is able to

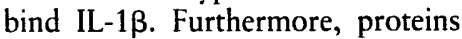
that bind to tumor necrosis factor (TNF) and to CC chemokines have been identified in the ORF of pox viral strains (B. Widmer, Seattle) and cytomegaloviruses (K. Neote, Groton), respectively.

\section{Cytokine receptors}

The cytokine receptors can be grouped into several families and subfamilies, as shown in Table 1.

\section{$I L-1$ and $I L-1 R$}

The genes for human IL- $1 \alpha$, IL-1 $\beta$ and IL-1 receptor antagonist (ra), as well as for IL-1R type I and II, are all located on chromosome 2 , suggesting that these factors are
New and exciting developments in the understanding of the interaction between cytokines and their recepturs, and the clinical application of cytokine antagonists, were discussed at a recent meeting*: Here, Reno Debets and Huub Savelkoul relisit this progress.

expressed in a coordinated fashion following cell activation. Crosslinking experiments have excluded the possibility of IL-1R typa II being a $\beta$-type receptor molecule, like the IL-6 signal transducer gp130 (J.E. Sims, Seattle). IL-1R type I and II clearly differ in the length of their cytoplasmic domains, comprising 213 and 29 amino acids, respectively. Indeed, the type II receptor is unable to transduce signals intracellularly after IL-1 binding. Moreover, IL-1 responsiveness only requires a few type I receptor molecules per cell, and these are probably expressed by all somatic cells, which is in accordance with the highly pleiotropic functions of IL-1. IL-1ra and IL- $1 \beta$ have similar, but not identical, three-dimensional structures (S.P. Eisenberg, Boulder). The binding of IL-1 ra to one binding site on IL-1R type I competitively blocks the binding of IL- $1 \alpha$ and IL-1 $\beta$, but does not induce an IL-1-like signal. IL-1R type I displays two binding sites for IL- $1 \alpha$ and IL- $1 \beta$, one of which is similar to the binding site for IL-1ra and the other differing in location depending on whether IL-1 1 or IL-1 $\beta$ is being bound. The latter binding site is necessary for receptor activation and signal transduction. Thus, receptor biluling and activation are two physicalily separate events.

"The meeting 'Regulation of Cytokine Activity for Therapeutic Development: Control of Inflammation, Growth and Differentiation' was held in Washington DC, USA, 3-4 March 1994.
In contrast to IL-1R type I, the type II receptor shows only significant binding affinity for $\overline{I L}-1 \beta$. Shedding of IL-1R type II from the cell surface sometimes occurs spontaneously, but can also be induced in vitro. Moreover, shedding occurs quickly and probably involves proteolysis. This shedding may represent a physiological attempt towards feedback signaling, since soluble (s)IL-1R type II acts as a specific antagonist of IL-1 $\beta$. Indeed, sIL-1R type II binds IL-1 $\beta$ and prevents an IL-1 response via cell-surface-bound IL-1R type I. Furthermore, IL-1R type II is upregulated by the antiinflammatory cytokine IL-4. Thus, since IL-1R type II appears to be predominantly expressed in the basal layer of epithelia, the receptor may act as a barrier mechanism whereby locally produced IL-1 $\beta$ is neutralized.

\section{IL-9 and IL-9R}

IL-9 stimulates the proliferation of early erythroid progenitor cells and acts in synergy with suboptimal doses of IL-4 for the production of IgG and IgE by murine B cells ( $\mathrm{J}-\mathrm{C}$. Renauld, Leuven). In IL-4 knockout mice, IL-9 expression is severely depressed. Moreover, IL-9 displays mast cell growth-enhancing activity and seems to be a potent regulator of mast cell effector molecules (e.g. IL-9 induces the production of proteases, IL- 6 and upregulates the expression of the FceRI $\alpha$-chain). Furthermore, lymph nodes from patients with Hodgkin's and largecell anaplastic lymphoma constitutively produce IL-9. The IL-SR, expressed on activated $T$ cells, has a single high-affinity binding site $\left(K_{\mathrm{d}}=20 \mathrm{pM}\right)$ for IL-9. The extracellular part of the IL-9R is highly homologous to the IL-2R $\gamma$-chain, 


\section{trends}

Table 1. Cytokine receptor families

\begin{tabular}{|c|c|}
\hline Families & Ligands \\
\hline $\begin{array}{l}\text { Class I (hematopoietic receptors) } \\
\text { common chain (gp } 130 \text { ) } \\
\text { B-chain } \\
\gamma \text {-chain }\end{array}$ & $\begin{array}{l}\text { IL-6, CNTF, OSM, LIF, IL-11 } \\
\text { IL-3, IL-5, GM-CSF } \\
\text { IL-2, IL-4, IL-7, (IL-13, IL-15) }\end{array}$ \\
\hline Class II (IFN receptors! & IFN \\
\hline lg supertamily receptors & IL-1, CSF-1, Steel factor, Flt3L \\
\hline TNF-like receptors & TNF, NGF, CD27L, C.D30L, CD40L \\
\hline G-protein-coupled receptors & Chemokines \\
\hline
\end{tabular}

Abbreviations: gp, glycoprotein; IL, inrerleukin; CNTF, ciliary neurotrophic factor; OSM, oncostatin Mi; LIF, leukemia inhibitory factor; GM-CSF, granulocytemacrophage colony-stimulating factor; IFN, interferon; Ig, immunoglobulin; C.SF-1, colony-stimulating factor 1: Flt3L, ligand of the fms-like tyrosine kinase; L, ligand; T.NF, rumor necrosis factor; NGF, nerve growth factor.

and substantial homology has also been observed between the cytoplasmic domains of the IL-9K and those of the IL-2R $\beta$-chain and the receptor for erythropoietin (EPOR).

\section{IL-15 and IL-15R}

A novel cDNA sequence has been isolated that corresponds to a $15 \mathrm{ki}$ a protein, termed IL-15, that displays IL-2-like functions but shares no significant structural homology with IL-2 (J.G. Giri, Seattle). It was found that the IL-15 mRNA is predominantly expressed in placenta and skeletal muscle tissue, and that IL-15 protein is produced by peripheral blood mononuclear cells (PBMCs), epithelial cells, fibro-

blasts and endothelial cells, but not by activated peripheral $\mathrm{T}$ cells. This pattern of protein expression is complementary to that of IL-2. Furthermore, the IL-2- and IL-15induced proliferation of PBMCs can be neutralized by antibodies against the IL-2R $\alpha$ - and $\beta$-chain respectively. Binding studies with phytohemagglutinin (PHA)-stimulated PBMCs have shown that these cells display only one class of binding site for IL-15, but display two classes of binding sites for IL-2. In IL-2-knockout mice, T-cell functions are normal, possibly due to IL-15 substituting for the deficient IL-2. However, in SCID mice, which lack the IL-2R $\gamma$-chain, IL-15 cannot

Table 2. Regulators of cytokine activity

\begin{tabular}{lc}
\hline Type & Possible mechanism of action \\
$\begin{array}{l}\text { Cytokine antagonists } \\
\text { Non-peptidic molecules }\end{array}$ & $\begin{array}{c}\text { Interfere with cytokine synthesis, receptor binding } \\
\text { or signal transduction }\end{array}$ \\
Soluble receptors & $\begin{array}{c}\text { Scavenge, neutralize and prevent extravascular } \\
\text { escape }\end{array}$ \\
IL-1ra/mutated cytokines & $\begin{array}{c}\text { Prevent induction of receptor-mediated signal } \\
\text { transduction }\end{array}$ \\
Autoantibodies & $\begin{array}{c}\text { Neutralize; enhance complcment-mediated } \\
\text { killing of cells expressing membrane-bound } \\
\text { or surface-receptor-bound cytokine }\end{array}$ \\
$\begin{array}{l}\text { Cytokine agonists } \\
\text { autole receptors/ }\end{array}$ & $\begin{array}{l}\text { Increase the persistence and chaperoning of } \\
\text { cytokines }\end{array}$
\end{tabular}

Abbreviation: II -1 ra, interleukin I receptor antagonist. substitute for the loss of IL-2 since it also requires the $\gamma$-chain for signal transduction. Triple-negative thymocytes express the IL-2R $\alpha$-, $\beta$ - and $\gamma$-chains, and yet are unresponsive to IL-15, suggecting the existence of a separate IL-15-binding IL-15R $\alpha$-chain.

\section{Regulation of cytokine activity}

Regulators of cytokine activity, displaying antagonistic as well as agonistic funct ons, are summarized in Table 2. Some of the antagonistic regulators may have therapeutic value.

\section{Non-peptidic antagonists}

Small, and preferabiy orally active, non-peptidic molecules are considered the ideal antagonists (G. Garotta, Basel). However, to date, the only effective antagonist has been isothiazolone $\mathrm{A}$, which interferes with IL-5 binding to its receptor ( $R$. De Vos, Gent).

\section{Soluble receptors}

Soluble cytokine receptors provide a natural source of highly selective cytokine inhibitors. However, apart from antagonizing cytokine activity, soluble receptors can also agonize cytokine activity, thereby acting as 'double-edged swords' (K.A. Clouse, Bethesda). Both these effects can result from the formation of complexes between the soluble receptor and its ligand, illustrating the carrier concept of soluble receptors.

Soluble receptors, such as sTNFRs, are monomeric. These receptors bind cytokine with less affinity than dimeric constructs generated as a chimeric immunofusion protein with human $\operatorname{IgG~Fc}$, as has been carried out for TNFR type I (K. Mohler, Seattle). The sTNFR-Ig construct by itself does not activate complement and does not bind to FcR. This construct blocks the lipopolysaccharide (LPS)-induced release of TNF- $\alpha$ in mice during the first 2-3 hours after IDS injection and can prevent a lethal outcome. In an animal model of inflammatory lung disease, infection with Micropolyspora faeni is known to induce the synthesis of TNF- $\alpha$ and IL- $1 \alpha$, and this is antagonized by the sTNFR-Ig construct. When the $M$. faeni antigen was given intranasally at a dose 


\section{trends}

of $75 \mu \mathrm{g}$ during days $1-3$, lung biopsies on days 4-7 showed infiltrates, primarily comprising neutrophils, in the alveoli. Addition of sTNFR-Ig prevented the infiltrate to a significant extent.

A sIFN- $\gamma \mathrm{R}-\mathrm{Ig}$ construct has been used in animal models of several diseases, including multiple sclerosis (MS) and systemic lupus erythematosus (SLE) (G. Garotta). For example, NZB/W $F_{1}$ mice spontaneously develop an SLE-like syndrome leading to mortality. The onset of kidney damage and mortality was significantly delayed by injection of sIFN- $\gamma \mathrm{R}-\mathrm{Ig}(100 \mu \mathrm{g}$. three times weekly, for 18 weeks), and this treatment prevented several symptoms of disease, including: the onset of membrane-proliferative glomerulonephritis; the infiltration of $T$ cells and macrophages into the kidney; the synthesis of IFN- $\gamma$ and TNF- $\alpha$; and the expression of major histocompatibility complex (MHC) class II, intercellular adhesion molecule 1 (ICAM-1), vascular cell adhesion molecule 1 (VCAM-1) and IFN- $\gamma \mathrm{R}$ on the tubular epithelium and the glomerular cells. Treatment with this construct also delayed, but did not block, the appearance of autoantibodies to double-stranded (ds)DNA. Moreover, such therapy was not effective if mice already had proteinuria and severely elevated serum levels of autoantibodies to dsDNA.

An animal model for acute bronchial eosinophilia was used to study the efficacy of either sIL-5R $\alpha$-chain or an immunofusion construct of this receptor (R. De Vos). Using IL-4-transgenic mice, sensitization with ovalbumin (OVA) caused increased levels of serum IgE. Challenge after two weeks with aerosols of OVA resulted in bronchial eosinophilic infiltrate and airway hyperresponsiveness. The eosinophilia could be inhibited effectively using either the sIL-5R $\alpha$-chain or the immunofusion construct.

A clear demonstration of the 'double-edged sword' phenomenon of cytokine receptors was presented by the murine sIL-4R (C.R. Maliszewski, Seattle). On the one hand, sIL-4R antagonizes IL-4 activity in models of murine ailoreactivity (e.g. heart allograft survival) as well as models of anti-IgD immunization (e.g. inhibition of IgE production). On the other hand, complexes of sIL-. $\mathrm{R}$ and IL-4 superinduce IgE responses during anti-IgD immunization. Furthermore, sIL-4R-transgenic mice expressing high levels of sIL-4R (e.g. in excess of $3 \mu \mathrm{g} \mathrm{ml}^{-1}$ ) displayed prolonged allograft survival. However, these mice also showed a normal antigen-specific IgE response by $B$ cells, suggesting that even $3 \mu \mathrm{g} \mathrm{ml}^{-1}$ of sIL-4R does not block the IL-4-induced synthesis of IgE. The $r_{c}$, between sIL-4R and IL-4 is crucial in determining the therapeutic usefulness of sIL-4R. The predominance of sIL-4R probably results in a shift away from a $T$ helper 2 (Th2) response, which is beneficial in the treatment of Th2-dominant disease situations such as allergy, asthma, parasitic infections and AIDS. However, complexes with II -4 are likely to result in a shift towards Th2, which is useful in the treatinent of Th1dominant helminth and mycobacterial infections.

\section{IL-1 ra}

Endogenous IL-1ra regulates the pathophysiological effects of IL-1 during acute inflammation (S.P. Eisenberg). In an acute model of immune colitis in rabbits, the kinerics of changes in $\mathbf{I L}-1 \hat{\alpha}$ levels was synchronous with the time course of inflammation, whereas changes in IL-1ra levels were delayed but prolonged when compared with the time course of inflammation. In normal colon tissue, IL-1 ra but not IL- $1 \alpha$ was detectable, and the maximum IL-1ra level during inflammation was approximately tenfold higher than the maximum IL- $1 \alpha$ level. The use of anti-IL-1ra antibody exacerbated inflammation, increased IL- $1 \alpha$ bioactivity and lowered the survival rate. IL-1ra increased the survival of rabbits and rats in endotoxin-induced shock. Although IL-1 ra aione is less effective in severe models of shock, synergism is exhibited with sTNFR type I with respect to increasing the survival rate.

\section{Mutated cytokines}

A mutant form of IL-4, in which the tyrosine residue at amino acid position 124 is replaced by aspartic acid (Y124D), displays a threedimensional structure similar to that of wild-type IL-4 (T. Mueller, Heidelberg). This mutant specifically blocked IL-4- and IL-13induced B-cell proliferation, as well as IgG4 and IgE synthesis, when cells were co-stimulated with anti-CD40 monoclonal antibody (mAb) (G. Aversa, Palo Alto). Thus, IL-4 mutants may be useful as IL-4 antagonists in the treatment of atopy. Analogs of granulocyte-macrophage colony-stimulating factor (GM-CSF), in which the glutamic acid residue at position 21 is replaced by arginine or lysine, are defective at binding to the $\beta$-chain of GM-CSFR, and antagonize GM-CSF activity (J. Bagley, Adelaide).

\section{Anticytokirie autoantibodies}

Recently, it was found that natural autoantibodies to cytokines occur under physiological conditions (K. Bendtzen, Copenhagen). Anticytokine autoantibodies are known to block bioactivity of the relevant cytokines, and can be found in the serum for IL- $1 \alpha$, IL- - , IFN- $\alpha$ and IL-10. These antibodies are most often of the IgG1 or IgG4 isotype and all show affinities in the pM range. Furthermore, some serum antibodies bind aspecifically to cytokines (e.g. T.M. IL-2, IL-4 and IL-8̂). Autoantibodies hive nố beeñ found against IL-1 $\beta$, IL-1ra, IL-3, IFN- $\beta$ or IFN- $\gamma$.

The 'double-edged sword' paradigm of soluble receptors also applies to anticytokine autoantibodies. Small complexes between such antibodies and cytokines are unable to activate complement if IgG4 antibodies are involved, and do not precipitate in vivo, but are active as inflammatory complexes. For these reasons, the therapeutic use of intravenous Ig preparations. displaying binding capacities for $\mathrm{I}-1 \alpha$ and IL-6, should be consicered carefully.

\section{Conclusion}

Findings presented at this meeting clearly demonstrate the therapeutic potential of cytokine antagonists. Non-peptidic antagonists (e.g. isothiazolone $\mathrm{A}$ ), soluble cytokine receptors (e.g. sTNFR, sIFN- $\gamma$ R and sIL-5R), the IL-1ra and mutated cytokines (e.g. iL-4 and GM-CSF) 


\section{trends}

may all be clinically useful, as demonstrated by transgenic and targeted mice, as well as animal models of disease and human diseases. However, for therapeutic purposes, one should consider the possible agonizing effects of soluble receptors and anticytokine autoantibodies (e.g. anti-IL-1 $\alpha$ autoantibody) on cytokine activity.

It was not possible to include all of the interesting presentations given at the meeting in this brief report. We thank our colleagues for their critical reading of this paper.

Reno Debets and Huub F.J. Savelkoul are at the Dept of Immunology, Erasmus University, PO Box 1738, 3000 DR Rotterdam, The Netherlands.

\section{Mucosal vaccines: high-tech reagents for low-tech immunization}

\section{Claude P. Muller}

Anitgens are usually poorly iinmunogenic when administered orally or intranasally and a variety of approaches have been designed to overcome this problem. Recently, the progress of six projects involving 24 laboratories funded iveness. Mucosal vaccines also provide a vehicle with which to target antigens directly to the largest lymphoid organ systems - those associated with the gut and the respiratory tract. In these organs, an effective local immune response may be required since they usually either constitute the route of entry of the pathogen or are prime targets of pathogen virulence. In some diseases, such as peptic ulcers, the bacterial agent (Helicobacter pylori) and mechanisms of host immunity are only now unfolding (S. Abrignani, Siena).

During Shigella flexneri infections, an immune response is elicited against lipopolysaccharide (LPS) and invasins. The relative contribution of the systuinic and local response to immune protection following natural or experimental infection with $S$. flexneri is not fully understood. However, it is now reported that $\operatorname{IgA}$ mediates a protective role against LPS (A. Phalipon, Paris). Attenuated live mutants of $S$. flexneri have been developed by genetic inactivation by the 'Human and Veterinary Vaccines' section of the EC Biotechnology programme were discussed at a meeting in Luxembourg*.

(P30 or SAG1) have not yet been shown to be protective in vivo. Chronic parasite persistence without significant complications could be exploited therapeutically by using $T$. gondii as a convenient carrier of heterologous proteins. The potent immunogenicity of the dense grañ-

of virulence factors, such as the proteins that mediate uptake of essential nutrients or mediate bacterial mobility. These mutants were efficient in protecting monkeys against homologous virulent strains ${ }^{1}$. In addition, such nonvirulent mutants may provide vaccine vectors for delivering heterologous antigens that have beer inserted into highly immunogeric secretory proteins (A. Phalipon).

A protective role of early $\operatorname{IgA}$ has also been suggested for Toxoplasma goindii infection, following the detection of specific secretory IgA molecules in human whey that were shown to neutralize the parasite in vitro. However, mouse monoclonal IgA antibodies directed against some of the major surface antigens of the tachyzoite

*The First European Laboratory Without Walls (ELWW) meeting on 'Mu o;al Immunity' was held in Luxembourg on 1-3 February 1994. ules of li:e Toxoplasma makes them an attractive vehicle to deliver secreted heterologous antigens (M-F. Cesbron, Lille). Indeed, the recent development of methods to manipulate tachyzoites genetically has opened up the possibility of introducing heterologous epitopes.

Synthetic vaccines and adjuvanis

While the protective role of the IgA response remains to be established in the systems described above, protective epitopes have already been defined at the level of short peptides in oth $=$ r syšstems. Current field studies with Schistosomainfected patients suggest that the IgA response to defined peptide analogues of the $S$. mansoni glutathione-S-transferase protein (Sm28GST) correlates with a reduction of parasite fecundity. Nionoclonal anti-IgA antibodies to such peptides were shown to reduce parasite fecundity by passive 